\title{
Una Sentencia trascendental sobre la inexistencia de plazo para interponer el recurso contencioso-administrativo frente al silencio administrativo negativo (*)
}

\author{
Eloísa Pérez Andrés \\ Profesora Asociada de la \\ Universidad Pablo de Olavide
}

\section{A) PLANTEAMIENTO}

El pasado 23 de Enero de 2004 el Tribunal Supremo ha dictado una sentencia de excepcional importancia sobre el plazo para interponer el recurso contencioso-administrativo cuando lo que se recurre es una desestimación presunta o silencio administrativo negativo.

El Art. 46 de la Ley 29/1998 reguladora de la Jurisdicción Contenciosoadministrativa dispone que el plazo para interponer el recurso contenciosoadministrativo será de dos meses si el acto que se impugna fuera expreso y de seis meses si no lo fuera, contándose en este caso el plazo desde el día siguiente a aquel en que se produzca el acto presunto. En aplicación de este precepto, los Tribunales de los Contencioso-administrativo, salvo importantes excepciones, han venido inadmitiendo aquellos recursos interpuestos contra desestimaciones presuntas de la Administración, cuando habían transcurrido más de seis meses desde que la desestimación se hubiera producido. De esta forma, los administrados, después de soportar la desidia de una Administración incumplidora de los plazos máximos para resolver, -en algunas ocasiones superiores a seis meses, incluso de años, cuando así lo disponga una norma con rango de Ley o comunitaria, tal y como autoriza el art. 42 de la Ley de Régimen Jurídico de las Administraciones Públicas y Procedimiento Administrativo Común-, además, se han visto perjudicados por el hecho de que el incumplimiento de la Administración deja su derecho a recurrir encerrado en

(*) Comentario publicado en el número 164 de la R.A.P. (pág. 201). 
un lapso de tiempo de obligado cumplimiento so pena de peder la posibilidad de defenderse.

Esta situación de injusticia había sido ya advertida y corregida en algún caso concreto por alguna resolución judicial; así el Auto de la sección $5^{\mathrm{o}}$ de la Sala de lo Contencioso-administrativo de del Tribunal Superior de Justicia de Madrid de 25 de Noviembre de 1999 fue pionero al admitir el recurso interpuesto fuera del plazo de seis meses del art. 46 de la LJCA contra la desestimación presunta de una reclamación económico-administrativa.

También la doctrina más autorizada venía defendiendo la inexistencia de un plazo para interponer el recurso contencioso cuando el objeto del mismo es una desestimación presunta. Entre esta doctrina administrativista destaca con especial fuerza y contundencia la voz del del Profesor. D. Eduardo García de Enterría ,que en la REDA no 105 comentaba el referido Auto de 25 de Noviembre de 1999 y exponía los argumentos fundamentales que determinan la no aplicación del plazo de los seis meses para recurrir contra el silencio administrativo negativo.

La sentencia del Tribunal Supremo de 23 de Enero de 1994 que ahora ha sido dictada, resuelve el Recurso de Casación en Interés de Ley núm 30/2003 interpuesto por la Diputación Provincial de Sevilla contra la sentencia del Juzgado de lo Contencioso-administrativo número dos de Sevilla dictada en el recurso 701/01, en la que se admitió el recurso contencioso interpuesto fuera del plazo de seis meses contra la desestimación presunta de recursos de reposición interpuestos contra liquidaciones de contribuciones especiales. La sentencia sienta doctrina resolviendo definitivamente sobre la aplicación del art. 46 de la LJ a los casos en los que la Administración incumple el deber de dictar resolución en plazo.

\section{B) ARGUMENTOS DOCTRINALES Y JUDICIALES CONTRA LA APLICACIÓN DEL PLAZO DE SEIS MESES DEL ART. 46 LJCA AL RECURSO CONTRA DESESTIMACIONES PRESUNTAS}

Antes de comentar esta trascendental sentencia hemos de analizar los argumentos que, tanto la doctrina como las resoluciones judiciales referidas, venían aplicando en defensa de la inaplicabilidad del plazo de seis meses para recurrir el silencio negativo:

1.Argumento lógico: Necesidad de coordinar el plazo de interposición del recurso contencioso con los efectos del silencio administrativo dispuesto en las 
normas reguladoras del procedimiento administrativo. Doctrina jurisprudencial reiterada.

El establecimiento de un plazo para recurrir la desestimación presunta producida por el incumplimiento por parte de la Administración de su deber de resolver ha de ser analizado no como un elemento aislado sino poniéndolo en relación con el régimen jurídico del silencio administrativo. Por ello es necesario hacer un análisis sucinto de la evolución tanto legislativa como jurisprudencial que en esta materia se ha producido:

Con la Ley de Procedimiento Administrativo de 1958, el silencio administrativo se configura como una garantía para los administrados que no excluye el deber de la Administración de resolver. Se trata de una ficción jurídica que deja expedita la vía judicial pero que no impedía una ulterior resolución expresa, sino que la Administración seguía estando obligada a dictarla conforme a los Arts. 94 de la Ley de Procedimiento Administrativo y 38 de la Ley de la Jurisdicción Contencioso-administrativo de 1956. En consecuencia esta última norma no establecía un plazo para interponer el recurso contencioso contra el silencio de la Administración, y la jurisprudencia mantuvo de forma reiterada que "no cabe apreciar extemporaneidad en la vía jurisdiccional cuando la Administración incumple su deber de resolver, ya que ésta viene obligada a dictar resolución expresa en cualquier caso como disponen los Arts. 94.3 de la Ley de Procedimiento Administrativo y 38.2 de la Ley de esta Jurisdicción" (Sentencias del Tribunal Supremo de 24 de Febrero de 1988, 31 de Enero de 1989, 4 de Mayo de 1990, 24 de Mayo de 1990, 22 de Marzo de 1997, 19 de Julio de 1997, 26 de Julio de 1997, 28 de Noviembre de 1998 entre otras).

Con la entrada en vigor de la Ley 30/92, sus Arts. 43 y 44 establecieron un régimen jurídico distinto ya que una vez producido el silencio administrativo y emitida la certificación del acto presunto desaparecía para la Administración el deber de resolver. De esta forma el silencio negativo no tenía el valor de ser una mera ficción jurídica que permitiera a los administrados recurrir sino que se consideraba como un verdadero acto administrativo de carácter desestimatorio que la Administración no podía modificar mediante una resolución dictada tardíamente. En concreto, el Art. 44 de la Ley 30/92 en su redacción originaria establecía:

"Si la certificación no fuese emitida en el plazo establecido en el apartado anterior, los actos presuntos serán igualmente eficaces y se podrán acreditar mediante la exhibición de la petición de certificación sin que quede por ello desvirtuado el carácter estimatorio o desestimatorio legalmente establecido para el acto presunto" 
El efecto del silencio administrativo era el mismo tanto en el caso de ser positivo como negativo: el ser un acto administrativo que hacía desaparecer la obligación de la Administración de dictar una resolución expresa. Estando en vigor este régimen jurídico del silencio administrativo se dictó la Ley 29/1998 reguladora de la Jurisdicción Contencioso-administrativa que, en concordancia con aquel, dispuso en su Art. 46 un plazo específico de seis meses para interponer el recurso contra cualquier acto presunto tanto estimatorio como desestimatorio.

Posteriormente, con la modificación operada en la Ley 30/92 por la Ley $\underline{4 / 99}$, ha vuelto a configurarse el silencio administrativo negativo o desestimatorio no como un acto administrativo sino como una ficción jurídica que opera como una garantía dejando expedita la vía judicial, pero manteniendo la obligación de la Administración de dictar una resolución expresa. El Art. 43.3 de la Ley 30/92 tal y como ha quedado redactado por la Ley 4/99 es claro al respecto cuando refiriéndose al efecto del silencio administrativo dispone:

"Las estimación por silencio administrativo tiene a todos los efectos la consideración de acto administrativo finalizador del procedimiento.

La desestimación por silencio administrativo tiene los solos efectos de permitir a los interesados la interposición del recurso administrativo o contencioso-administrativo que resulte procedente"

Esta nueva configuración del silencio administrativo que vuelve al sistema anterior a la Ley 30/92, impone necesariamente la aplicación de la doctrina jurisprudencial citada sobre la inexistencia de un plazo preclusivo para recurrir contra las desestimaciones presuntas, habiendo de entenderse derogado el Art. 46 de la Ley Jurisdiccional en este punto.

\section{Interpretación literal.}

De la interpretación literal de los preceptos de la Ley 4/1999 y la Ley 29/1998 se deduce de manera clara que la referida derogación se ha producido ya que el Art. 46 de la Ley Jurisdiccional al regular el plazo de impugnación se refiere a actos presuntos y, conforme a la Ley $30 / 92$ tal y como ha quedado redactada por la Ley 4/1999, no hay actos presuntos desestimatorios, sino que el silencio negativo, como hemos dicho es una mera ficción, una ausencia de acto que permite entender desestimadas las pretensiones. 


\section{Argumento teleológico.}

Un argumento teleológico determina asimismo la derogación del plazo de seis meses dispuesto por el Art. 46 de la Ley Jurisdiccional, ya que el fin que está llamado a cumplir el silencio administrativo, la razón de su configuración jurídica es el constituir una verdadera garantía frente a la omisión por parte de la Administración del deber que la Ley le impone de resolver expresamente los procedimientos. En consecuencia, el incumplimiento de esta obligación legal nunca puede beneficiar a la Administración y constituir una carga para el particular viéndose obligado además de soportar la incertidumbre del silencio administrativo, a accionar contra el mismo en un plazo concreto y determinado so pena de perder las posibilidades de defenderse.

En este sentido, la falta de interposición de un recurso contencioso administrativo en el plazo de 6 meses contra una desestimación presunta nunca puede dar lugar a un "acto consentido", no sólo porque, como se ha expuesto, la desestimación por silencio no tiene el carácter de verdadero acto administrativo, sino porque en ese caso el silencio negativo habría operado justamente como una carga para el particular que, además de soportar la desidia de la Administración vería encerrado o limitado en un plazo de tiempo su derecho a defenderse.

\section{$\underline{\text { 4. Necesidad de preservar la seguridad jurídica y el derecho a la defensa. }}$}

Si partimos de la aplicación del plazo de seis meses del art. 46 de la LJCA para recurrir el silencio administrativo negativo, habría de admitirse que en caso de que dicho período de tiempo hubiera trascurrido, si la Administración entonces resolviera expresamente se abriría nuevamente el plazo de dos meses para interponer el recurso contencioso administrativo en este caso contra un acto expreso.

Con ello se llega al resultado ilógico de que la Administración se beneficiaría de su propio incumplimiento e incluso sería de su interés mantenerlo ya que, por un lado, como se ha dicho, la consecuencia de la falta de resolución sería que las posibilidades de defensa de los administrados quedarían encerradas en lapsos de tiempo concretos y, una vez transcurridos y en contraste con esta limitación temporal, para convertir la situación de indefensión en irreversible bastaría con que la Administración prolongara indefinidamente su incumplimiento a fin de que no se volviera a abrir el plazo para recurrir en este caso contra un acto expreso tardío. En definitiva este planteamiento no hace más que alentar a la Administración a incumplir el deber de resolver impuesto por el art. 42 de la Ley 30/92. En este caso el derecho a la defensa de los administrados se 
hace depender única y exclusivamente de que la Administración decida o no dictar en el futuro una resolución expresa lo que resulta inadmisible para la seguridad jurídica garantizada por el Art. 9.3 de la Constitución.

5. Contradicción del Art. 46 de la Ley 29/1998 con el Art. 58.3 de la Ley 30/92 redactado por la Ley $4 / 1999$ y la jurisprudencia del Tribunal Supremo.

Finalmente, la incompatibilidad y contradicción del Art. 46 de la Ley 29/1998 y las modificaciones introducidas por la Ley 4/1999 en la Ley 30/1992 se hacen patentes al hacer una interpretación sistemática del referido Art. 46 poniéndolo en relación con el Art. 58.3 de la Ley 30/1992 en su nueva redacción.

En concreto, el referido Art. 58.3 dispone:

"Las notificaciones que conteniendo el texto integro del acto omitiesen alguno de los demás requisitos previstos en el apartado anterior surtirán efecto a partir de la fecha en que el interesado realice actuaciones que supongan el conocimiento del contenido y alcance de la resolución o acto objeto de notificación o resolución, o se interponga cualquier recurso que proceda".

Es doctrina jurisprudencial reiterada (entre otras en las Sentencias del Tribunal Supremo de 14 de Octubre de 1992, y de 3 de Octubre de 1994), que a lo más que puede llegar el silencio administrativo es a operar y producir los mismos efectos que una notificación defectuosa, ya que, aun cuando se considerara como un verdadero acto presunto (cosa que, como hemos visto, no hace la regulación actual en el caso del silencio negativo), siempre faltarían elementos como la, indicación de si el acto pone o no fin a la vía administrativa y, en su caso, que recursos podrían interponerse contra el mismo.

En consecuencia si, en tanto que no se interpone el recurso procedente (el recurso contencioso en su caso) contra el silencio administrativo, el mismo no produce efectos, esto resulta incompatible con la imposición de un plazo preclusivo para interponer el recurso contencioso contra las desestimaciones presuntas, plazo que sí podría tener sentido en la regulación anterior en la que, conforme a la redacción originaria del Art. 44 de la Ley 30/92, la eficacia del silencio administrativo estaba conectada a la solicitud por el administrado de emisión por la Administración de la certificación del acto presunto (Art. 44.2: "Para su eficacia, los interesados o la propia Administración deberán acreditar los actos presuntos mediante certificación emitida por el órgano competente que debió resolver expresamente el procedimiento, que deberá extenderla inexcusablemente en el plazo de veinte días desde que le fue solicitada salvo que en dicho plazo haya dictado re- 
solución expresa, sin que pueda delegar esa competencia específica”). Al haber desaparecido la exigencia de certificación del acto presunto y al haberse configurado en la forma expuesta el régimen jurídico de la notificación defectuosa, ha de mantenerse necesariamente que el Art. 46 de la Ley Jurisdiccional en cuanto que dispone el plazo de seis meses para impugnar las desestimaciones presuntas ha quedado derogado.

\section{Lex posterior derogat lex anterior}

En definitiva, estamos ante un problema de vigencia de normas ya que la Ley 4/99 como norma posterior y de igual rango que la Ley 29/1998 puede proceder perfectamente y ha procedido, a la derogación de esta última en todo aquello en lo que hemos visto se oponen y, en concreto, en el establecimiento de un plazo preclusivo para la interposición del recurso contencioso administrativo contra las desestimaciones presuntas producidas por el incumplimiento por parte de la Administración del deber de resolver.

\section{C) SENTENCIA DEL TRIBUNAL SUPREMO DE 23 DE ENERO DE 2004 POR LA QUE SE RESUELVE EL RECURSO DE CASACIÓN EN INTERÉS DE LEY 30/03}

La sentencia del Juzgado de lo Contencioso-administrativo número dos de Sevilla de 31 de Diciembre de 2002 dictada en el recurso 701/01, estimó los argumentos expuestos rechazando la inadmisibilidad del recurso al no ser aplicable el plazo preclusivo de seis meses del art. 46 de la LJCA:

"El art. 46 LJCA se refiere sin duda al plazo para recurrir ante ese orden jurisdiccional respecto de actos presuntos, diciendo que 'si no lo fuera (expreso, el acto que ponga fin a la vía administrativa), el plazo será de seis meses y se contará para el solicitante y otros posibles interesados a partir del día siguiente a aquel en que, de acuerdo con su normativa específica, se produzca el acto presunto'. Más tratándose de silencio negativo, desde la reforma de la Ley 30/92, ya no cabe hablar de actos presuntos desestimatorios sino sólo -nuevamente- de ficción legal que abre la posibilidad de impugnación, en beneficio del interesado. Así resulta de la nueva redacción del art. 43.3 de dicha Ley de Procedimiento Administrativo Común, al diferenciar los efectos del silencio estimatorio y desestimatorio, señalando para este último - a diferencia del primero o positivo- que la 'desestimación por silencio administrativo tiene los solos efectos de permitir a los interesados la interposición del recurso administrativo o contencioso administrativo que resulte procedente' Para la estimación por silencio se dice que tiene a todos los efectos la consideración de acto administrativo finalizador del procedimiento. Para la desestimación, por el con- 
trario, tiene 'los solos efectos' dichos. Por ello, el supuesto de desestimaciomes por silencio negativo ya no puede entenderse comprendido en la previsión del art. 46.1 de la LJCA, promulgada en momento en que la Ley 30/92 sí parecía considerar tales desestimaciones como verdaderos actos y no simplemente como una ficción legal"

Contra dicha sentencia se interpuso Recurso de Casación en Interés de Ley por la Administración solicitando que se declarara como doctrina legal la siguiente: "El plazo para interponer el recurso contencioso administrativo frente a actos presuntos negativos, esto es, desestimatorios de la pretensión, es el establecido en el art. 46.1 de la LJCA, es decir el de seis meses a partir del día siguiente a aquel en que, de acuerdo con su normativa específica, se produzca el acto presunto"

Dos eran los argumentos empleados por la Administración como base del recurso: por un lado, de carácter material, se alega la vulneración a la seguridad jurídica que supone el que juegue en cada caso un plazo para recurrir contra el silencio de la Administración; por otro lado, un argumento de carácter formal al entender que el plazo de interposición del recurso que literalmente establece el art. 46 LJCA es de seis meses y que por tanto ha de aplicarse a todos los supuestos de silencio administrativo.

Ambos argumentos han sido rechazados por el Tribunal Supremo de forma contundente:

En cuanto al argumento de seguridad jurídica, el Tribunal Supremo en el fundamento jurídico segundo de la Sentencia, da la vuelta al planteamiento de la Administración, haciendo recaer sobre la misma la responsabilidad de la situación de inseguridad creada por ella al incumplir los plazos máximos para resolver los procedimientos:

"El argumento acerca del quebrantamiento de la seguridad jurídica que el escrito de interposición del recurso contiene, es sorprendente.

La Administración no puede ocultar, ni desconocer, que es ella quien genera la situación de inseguridad al no dictar resolución expresa. Tampoco puede obviar que esa omisión constituye un frontal incumplimiento del mandato contenido en el art. 42.1 de la Ley de Régimen Jurídico de las Administraciones Públicas y del Procedimiento Administrativo Común.

Siendo esto así, como lo es, no es de recibo que quien genera mediante una conducta claramente ilegal y contraria al ordenamiento una situación de inseguridad jurídica pueda esgrimir esa inseguridad a su favor, pretendiendo obtener ventajas frente a quienes sufren los efectos de la inseguridad creada. 
Hemos dicho de modo reiterado, que nadie puede obtener beneficios de sus propios errores, omisiones e infracciones. Y esto, y no otra cosa, es lo que la Administración pretende cuando opone la inseguridad jurídica que se deriva de un estado de cosas que tiene su origen en su propio incumplimiento al no resolver los procedimientos pendientes, pues el modo lógico, natural, legal y que demanda la naturaleza de las cosas, para hacer cesar el estado de inseguridad que se denuncia es el decidir las cuestiones planteadas. Por eso, la Administración, mediante el cumplimiento de la ley, puede hacer cesar, de raíz, el estado de inseguridad jurídica, de cuya existencia aquí se lamenta”.

En cuanto al argumento de orden formal, el Tribunal Supremo da especial relevancia en el fundamento jurídico tercero de la sentencia a la doctrina jurisprudencial ya citada, mantenida también por el Tribunal Constitucional -sentencias 204/1987 y 63/1995-, que atribuye al silencio negativo los mismos efectos que si se tratara de una notificación defectuosa que solo sería eficaz si el particular interpusiese el recurso procedente. Además esa doctrina se ve reforzada, por lo dispuesto el el art. 42.4.2 ${ }^{\circ}$ de la Ley de Régimen Jurídico de las Administraciones Públicas y Procedimiento Administrativo Común:

"En todo caso, las Administraciones Públicas informarán a los interesados del plazo máximo normativamente establecido para la resolución y notificación de los procedimientos, asi como de los efectos que pueda producir el silencio administrativo, incluyendo dicha mención en la notificación o publicación del acuerdo de iniciación de oficio, o en comunicación que se les dirigirá al efecto en el plazo de los diez días siguientes a la recepción de la solicitud en el registro del órgano competente para su tramitación. En este último caso, la comunicación indicará además la fecha en que la solicitud ha sido recibida por el órgano competente”

Sobre ello dispone el Tribunal Supremo de forma contundente:

"La exégesis de este texto (art. 42.4.2 ${ }^{\circ}$ LPAC), complementada con la doctrina constitucional antes transcrita (que equipara los efectos del silencio negativo a la notificación defectuosa), obliga a concluir que en tanto las Administraciones Públicas no informen a los interesados de los extremos a que dicho precepto se refiere, los plazos para la interposición de los recursos no empiezan a correr".

Finalmente, la Sentencia no considera derogado el art. 46 de la LJCA por la Ley 4/99 sino que simplemente hace una interpretación precisa del mismo declarando que, tras la configuración del silencio administrativo negativo establecida por la Ley 4/99 como una ficción jurídica, el mismo ha dejado de estar en incluido en la literalidad y, en consecuencia, en el ámbito de aplicación del art. 46 de la LJCA: 
"Que la remisión que el art. 46.1 de la Ley Jurisdiccional hace al acto presunto, no es susceptible de ser aplicada al silencio negativo, pues la regulación que del silencio negativo se hace en la LRJAP y PC lo configura como una ficción y no como un acto presunto"

Con esta sentencia, el Tribunal Supremo viene a aclarar e interpretar la Ley habiéndola más justa y poniendo fin, para el futuro, a una situación de inseguridad e injusticia que durante un tiempo, felizmente ya pasado, ha legitimado situaciones de auténtica denegación del derecho a la defensa. Sentencias como esta, sin duda, afianzan el sometimiento de todos a la Ley, y con fortalecen nuestro Estado de Derecho. 